\title{
Balanço dos principais crimes cibernéticos ocorridos no município de Belém/PA no
} período de 2018 a 2020

Balance of the main cyber crimes that occurred in the municipality of Belém/PA in the period 2018 to 2020

\section{Balance de los principales delitos cibernéticos ocurridos en el municipio de Belém/PA en el período}

2018 a 2020

Recebido: 28/12/2021 | Revisado: 03/01/2022 | Aceito: 07/01/2022 | Publicado: 11/01/2022

\author{
Luciana Corrêa e Silva \\ ORCID: https://orcid.org/0000-0002-8665-7155 \\ Universidade Federal do Sul e Sudeste do Pará, Brasil \\ E-mail: lucianacsilva@unifesspa.edu.br \\ Diego de Azevedo Gomes \\ ORCID: https://orcid.org/0000-0002-4005-8579 \\ Universidade Federal do Sul e Sudeste do Pará, Brasil \\ E-mail: diagomes@unifesspa.edu.br
}

\begin{abstract}
Resumo
Este estudo objetivou investigar a dinâmica de crimes cibernéticos ocorridos no município de Belém/PA no período de 2018 a 2020 fazendo o levantamento dos crimes cibernéticos mais prevalentes, classificando-os, além de identificar o perfil das vítimas deste tipo de crime. Para alcançar tal objetivo, usou-se neste estudo, procedimentos oriundos da pesquisa bibliográfica, documental e pesquisa de campo. Para a pesquisa de campo foi realizada coleta de dados estatísticos, referentes aos crimes cibernéticos, produzido pela Secretaria de Segurança Pública do Estado do Pará. Sendo que, a metodologia empregada para o desenvolvimento dos gráficos se baseia na utilização da linguagem de programação Python para processamento e análise de grande quantidade de dados. Assim sendo, o estudo se debruça em abordagem quantitativa, análise estatística e interpretação dos dados. Os dados possibilitaram identificar que o crime de maior destaque foi o crime de Estelionato, seguido dos crimes contra honra (calúnia, injúria e difamação) e o crime de invasão de dispositivo informático. Notou-se ao perfil das vítimas que, quanto ao sexo, a prevalência maior foi do sexo feminino; ao quesito profissão, foi identificado vítimas nos mais variados e independentes seguimentos profissionais; em relação a faixa etária, a maior prevalência está entre os adultos de 35 a 65 anos de idade; A região de Belém com maior ocorrência de crimes cibernéticos está no distrito central do município, onde se concentra os bairros de classe média alta da capital do Estado do Pará.
\end{abstract}

Palavras-chave: Crimes cibernéticos; Internet; Legislação.

\begin{abstract}
This study aimed to investigate the dynamics of cyber crimes that occurred in the city of Belém/PA in the period 2018 to 2020, making a survey of the most prevalent cyber crimes, classifying them, in addition to identifying the profile of victims of this type of crime. In order to achieve this objective, in this study, procedures derived from bibliographical, documental and field research were used. For the field research, statistical data was collected, referring to cyber crimes, produced by the Secretariat of Public Security of the State of Pará. and analysis of large amounts of data. Therefore, the study focuses on a quantitative approach, statistical analysis and data interpretation. The data made it possible to identify that the most prominent crime was the crime of Estelionato, followed by crimes against honor (slander, libel and defamation) and the crime of invading a computer device. It was noted in the profile of victims that, in terms of gender, the highest prevalence was female; regarding profession, victims were identified in the most varied and independent professional segments; in relation to age group, the highest prevalence is among adults aged 35 to 65 years old; The Belém region with the highest incidence of cybercrime is in the central district of the city, where the upper middle class neighborhoods of the capital of the State of Pará are concentrated.
\end{abstract}

Keywords: Cyber crimes; Internet; Legislation.

\section{Resumen}

Este estudio tuvo como objetivo investigar la dinámica de los delitos cibernéticos ocurridos en la ciudad de Belém / PA en el período 2018 a 2020, realizando un relevamiento de los delitos cibernéticos más prevalentes, clasificándolos, además de identificar el perfil de las víctimas de este tipo de delito. Para lograr este objetivo, en este estudio se utilizaron procedimientos derivados de la investigación bibliográfica, documental y de campo. Para la investigación 
de campo, se recopilaron datos estadísticos, referidos a los delitos cibernéticos, elaborados por la Secretaría de Seguridad Pública del Estado de Pará. Y análisis de grandes cantidades de datos. Por tanto, el estudio se centra en un enfoque cuantitativo, análisis estadístico e interpretación de datos. Los datos permitieron identificar que el delito más destacado fue el de Estelionato, seguido de los delitos contra el honor (calumnias, calumnias y difamación) y el delito de invasión de dispositivo informático. En el perfil de víctimas se observó que, en términos de género, la mayor prevalencia fue femenina; en cuanto a la profesión, las víctimas fueron identificadas en los segmentos profesionales más variados e independientes; en relación al grupo de edad, la mayor prevalencia se da entre los adultos de 35 a 65 años; La región de Belém con mayor ocurrencia de delitos cibernéticos se encuentra en el distrito central de la ciudad, donde se concentran los barrios de clase media alta de la capital del Estado de Pará.

Palabras clave: Delitos cibernéticos; Internet; Legislación.

\section{Introdução}

A evolução tecnológica, o fácil acesso à internet e a redução nos preços dos computadores e dispositivos móveis fez com que a utilização da internet aumentasse consideravelmente nos últimos anos (Wendt \& Jorge, 2013). Tal evolução trouxe a ampla dependência da segurança e eficiência da Tecnologia da Informação nas relações sociais, na administração pública e sociedade em geral (Crespo, 2011). Entretanto, também ocorreu o beneficiamento para as ações e práticas criminosas, as quais evoluíram e adaptaram-se surgindo os chamados cibercrimes (Demeau et al. 2019).

Toda atividade em que um computador ou uma rede de computadores é utilizada como uma ferramenta, base de ataque ou como meio de crime é conhecida por cibercrimes (Cassanti, 2014). Corroborando com tal definição, Correia e Jesus (2016) conceituam crime informático como o cometimento de ações ilícitas em que se usa a informática para executá-lo, os autores enfatizam ainda, que este tipo de ilícito é de difícil detecção e prova. Para Garcia et al. (2018), o impulso para o crime cibernético advém de demandas pessoais, que se ativam na direção da prática ilegal e imoral

Considerando o surgimento e crescimento de práticas de crimes em meio virtual, foram criadas as Leis $\mathrm{n}^{\circ} 12.735$ e $\mathrm{n}^{\circ}$ 12.737, ambas de 30 de novembro de 2012, as quais são tidas como marco jurídico para frear os avanços de crimes em ambientes virtuais no Brasil, uma vez que, as referidas leis alteraram artigos do Código Penal e do Código Penal Militar para tipificar as condutas praticadas em âmbito eletrônico, digital e similares. É relevante destacar a redação do art. $4^{\circ}$ da Lei $n^{\circ}$ 12.735/2012 onde determina que "os órgãos da polícia judiciária estruturarão, nos termos de regulamento, setores e equipes especializadas no combate à ação delituosa em rede de computadores, dispositivo de comunicação ou sistema informatizado" (Brasil, 2012).

Ao código penal foram inseridos os Arts. 154-A e 154-B, em virtude da lei $\mathrm{n}^{\circ} 12.737 / 2012$, a qual trata dos chamados crimes informáticos.

Art. 154-A. Invadir dispositivo informático alheio, conectado ou não à rede de computadores, mediante violação indevida de mecanismo de segurança e com o fim de obter, adulterar ou destruir dados ou informações sem autorização expressa ou tácita do titular do dispositivo ou instalar vulnerabilidades para obter vantagem ilícita (Brasil, 2012).

Art. 154-B. Nos crimes definidos no art. 154-A, somente se procede mediante representação, salvo se o crime é cometido contra a administração pública direta ou indireta de qualquer dos Poderes da União, Estados, Distrito Federal ou Municípios ou contra empresas concessionárias de serviços públicos (Brasil, 2012).

Outra alteração pertinente se deu ao art. 266 do Código Penal, Decreto-Lei n n 2.848/1940 "Interromper ou perturbar serviço telegráfico, radiotelegráfico ou telefônico, impedir ou dificultar-lhe o restabelecimento" (Brasil, 1940) com acréscimo de dois parágrafos: $§ 1^{\circ}$ "Incorre na mesma pena quem interrompe serviço telemático ou de informação de utilidade pública, ou impede ou dificulta-lhe o restabelecimento" e $\S 2^{\circ}$ "Aplicam-se as penas em dobro se o crime for cometido por ocasião de calamidade pública" incluído pela Lei 12.737/2012.

O crime de falsificação de cartão também foi inserido ao Código Penal, com o advento da Lei no 12.737/2012, que acrescentou o parágrafo único ao art. 298: "Para fins do disposto no caput, equipara-se a documento particular o cartão de 
crédito ou débito" (Brasil, 2012). Ademais, na legislação brasileira, foi também sancionada a lei no 12.965/2014, a qual em seu Art. $1^{\circ}$ "estabelece princípios, garantias, direitos e deveres para o uso da internet no Brasil e determina as diretrizes para atuação da União, dos Estados, do Distrito Federal e dos Municípios em relação à matéria” (Brasil, 2014). A referida lei em seu Art. $7^{\circ}$ dispõem que:

Art. $7^{\circ}$. O acesso à internet é essencial ao exercício da cidadania, e ao usuário são assegurados os seguintes direitos:

I - Inviolabilidade da intimidade e da vida privada, sua proteção e indenização pelo dano material ou moral decorrente de sua violação;

II - Inviolabilidade e sigilo do fluxo de suas comunicações pela internet, salvo por ordem judicial, na forma da lei;

III - inviolabilidade e sigilo de suas comunicações privadas armazenadas, salvo por ordem judicial. (Brasil, 2014).

É importante salientar que a inviolabilidade da intimidade e da vida privada já são direitos garantidos por nossa Constituição Federal de 1988, conforme versa o Inc. X, do Art. $5^{\circ}$ da CF/1988: "são invioláveis a intimidade, a vida privada, a honra e a imagem das pessoas, assegurado o direito a indenização pelo dano material ou moral decorrente de sua violação" (Brasil, 1988). Embora a época da promulgação de nossa Carta Magna não se vislumbrava que a revolução tecnológica alcançaria os patamares dos dias atuais, pode-se dizer que o legislador teve a consciência racional no que tange a privacidade $\mathrm{e}$ a intimidade, independente da época, em que se vive, são bens jurídicos tutelados intrínsecos dos homens.

Portanto, "o direito à privacidade, em sentido mais estrito, conduz à pretensão do indivíduo de não ser foco da observação por terceiros" (Mendes et al. 2008). Entende-se com tal afirmação que, em virtude da rápida divulgação através dos meios eletrônicos de quaisquer matérias, seja da vida pública e/ou da vida particular tal direito encontra-se cada vez mais infringido ao ponto de ser necessária a criação de novas leis para se frenar danos irreparáveis provocados pelo descumprimento, moral e ético dos usuários da internet, a ponto de migrarem para o campo criminal.

Sendo assim, Zuboff (2020, p.14), afirma que:

"A realidade digital está tomando conta e redefinindo tudo que é familiar, antes mesmo de termos tido a chance de ponderar e decidir sobre a situação. Nós celebramos o mundo conectado por causa das muitas maneiras pelas quais ele enriquece nossas capacidades e perspectivas, mas ele gerou novos grandes territórios de ansiedade, perigo e violência conforme o senso de um futuro previsível se esvai por entre nossos dedos" (Zuboff, 2020).

Ante ao exposto, embora as legislações sejam de extrema importância, inclusive simbólica, não é uma condição definitiva para a erradicação dos crimes (Menezes \& Cavalcanti, 2017). Dessa forma, é relevante levar em consideração as interações sociais entre indivíduos e máquinas e suas atitudes de segurança cibernética e comportamento (Benson et al. 2018) (tradução nossa). De modo que, "há uma grande necessidade de refletir o impacto da informação na sociedade digital e suas implicações diretas e indiretas no estabelecimento de novos padrões de moralidade e ética" (Azevedo et al, 2015) (tradução nossa). Desse modo, Viana e Meneghett (2020, p.9) alertam para "falta de percepção dos usuários sobre as reais consequências dessa conectividade" (tradução nossa). A ideia de liberdade sem limites, deixa-nos vulneráveis, não vigilantes ao perigo iminente que pode surgir. A internet, para os usuários, não é apenas espaço de lazer, é espaço de trabalho, de estudos e infelizmente de muitos perigos.

Diante desta realidade de tendência para a prática de crimes em ambientes virtuais, busca-se neste estudo fazer um balanço dos principais crimes cibernéticos ocorridos no município de Belém/PA no período de 2018 a 2020, bem como, classificá-los, além de identificar o perfil das vítimas destes crimes. Por meio desta pesquisa científica serão ampliados os conhecimentos acerca da temática envolvendo ambientes virtuais, possibilitando assim, entender um contexto mais amplo desse processo, adicionando pontos e aspectos que outrora não haviam sido difundidos. 


\section{Metodologia}

\section{1 Área de estudo}

O município de Belém/PA, capital do estado do Pará, de acordo com o Instituto Brasileiro de Geografia e estatística (IBGE) (2021) possui população estimada de 1.506 .420 habitantes, sendo que a área territorial é de 1.059,466 km² e está dividido em 08 (oito) distritos. De acordo com a Lei no 7. 806, de 30 de julho de 1996, o município possui 72 (setenta e dois) bairros (Pará, 1996).

Figura 1: Mapa de localização de Belém/PA.

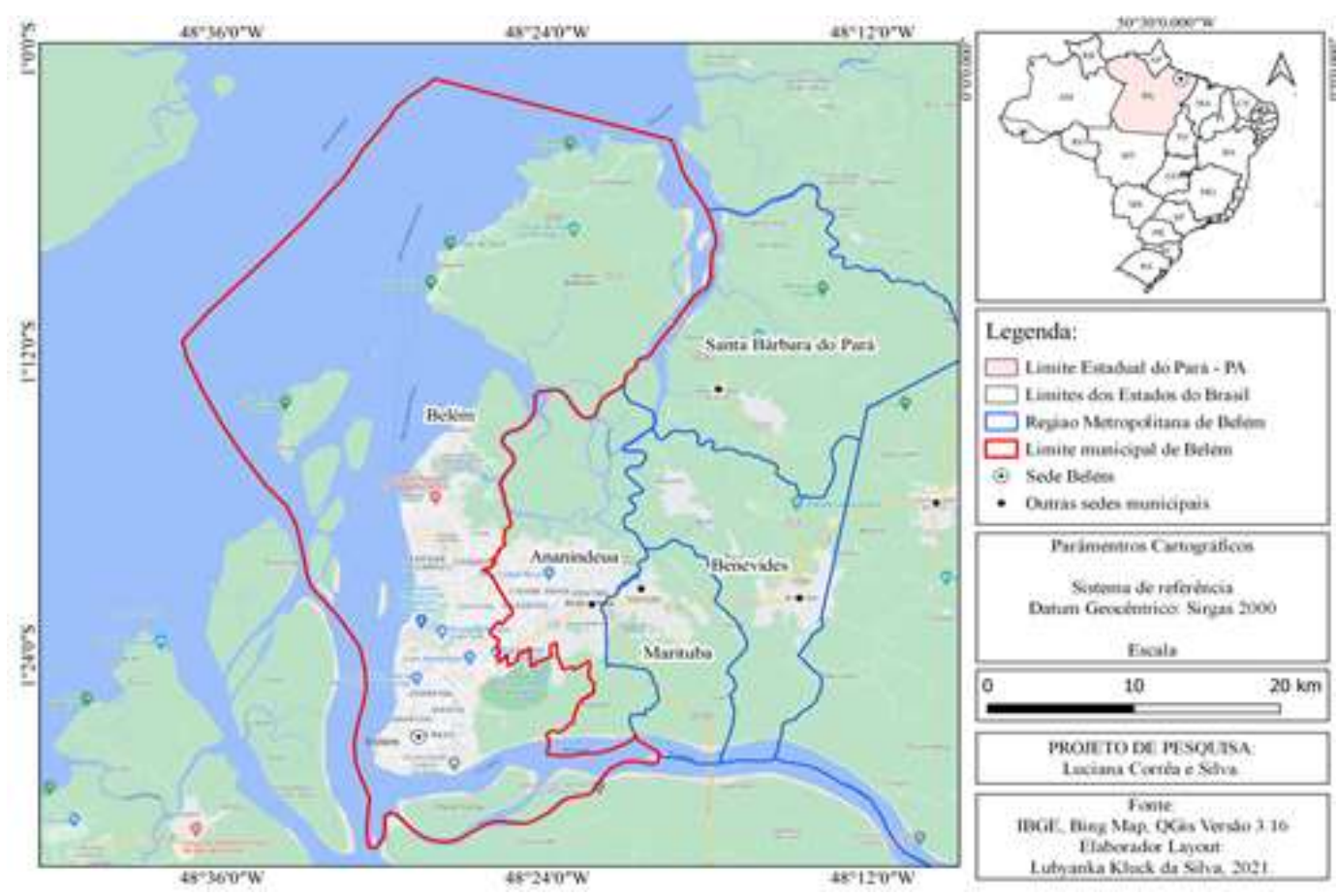

Fonte: Autores (2021).

\subsection{A pesquisa}

A pesquisa possui abordagem quantitativa, pois, de acordo com Gerhardt e Silveira (2009) a referida abordagem se fundamenta na quantificação de dados, enfatizando o raciocínio dedutivo e regras lógicas. Os procedimentos desta pesquisa são oriundos da pesquisa bibliográfica, pois, usou-se como embasamento teórico fontes bibliográficas que discorrem sobre o tema proposto, bem como, da pesquisa documental, na qual foi utilizada as legislações existentes no país que busca coibir as práticas de ações criminosas em ambientes virtuais.

Outrossim, para dar sustentabilidade a pesquisa, fez-se coleta de dados estatísticos e análise estatística de dados, referentes aos crimes cibernéticos, produzido pela Secretaria de Segurança Pública do estado do Pará. Assim sendo, o estudo se debruça em abordagem quantitativa, análise estatística e interpretação dos dados.

\subsection{Coleta de dados}

A coleta de dados se deu junto a Secretaria de Segurança Pública do Estado do Pará - SEGUP, a fim de se verificar a evolução temporal da ocorrência de crimes cibernéticos na região de estudo, a pesquisa abrangerá dados de uma série histórica de 2018 a 2020. 


\subsection{Análise de dados.}

A metodologia empregada para o desenvolvimento dos gráficos que expõem os dados relativos a crimes cibernéticos praticados na Região de Belém/PA se baseia na utilização da linguagem de programação Python e da plataforma google colab para processamento e análise de grande quantidade de dados. As informações presentes em uma planilha no formato .xlsx, foram importadas para dentro da plataforma do Google Colaboratory (Google Colab) onde é possível utilizar a linguagem python de forma otimizada sem que seja necessário acolar memória do computador para o processamento dos dados reduzindo, com isso, o custo computacional.

No interior do Google Colab, foram importados da linguagem python os pacotes (bibliotecas) necessárias para a leitura e processamento dos dados, bem como a manipulação dos mesmos a fim de gerar gráficos que auxiliam no desenvolvimento do trabalho. Dentre os pacotes utilizados, estão o Pandas para análise de banco de dados, Numpy para funções algébricas, matplotlib.pyplot para plotagem de gráfico e geração de figuras e por último o pacote scipy que possui diversas funções relacionadas à análises estatísticas descritivas. Algumas manipulações do banco de dados foram necessárias para a correta apresentação e interpretação dos dados. Por isso, os bairros presentes na planilha foram agrupados por distritos de acordo com os dados da Prefeitura Municipal de Belém. Além disso, o ano foi classificado de forma numérica para facilitar a identificação e o mesmo foi realizado para outros filtros presentes no banco de dados.

Para cada gráfico ou informação específica desejada, foi gerado um dicionário em que constou os dados de interesse, o que facilitou no desenvolvimento dos gráficos de barras. Para melhor customização dos gráficos, após a realização de todas as manipulações necessárias, os códigos para geração dos gráficos foram exportados para a IDLE nativa do python que é instalada localmente no PC. Com isso, evitou-se sobrecarregar a máquina visto que foi utilizado memória RAM apenas para plotagem de gráficos e não mais para análise de dados.

\section{Resultados e Discussão}

Diante dos resultados obtidos, foi possível perceber o crescimento contínuo de ocorrências de crimes cibernéticos, ao longo da série histórica que compreende os anos de 2018, 2019 e 2020, como demonstra a Figura 2: 
Figura 2: Análise de ocorrência de crimes cibernéticos por ano.

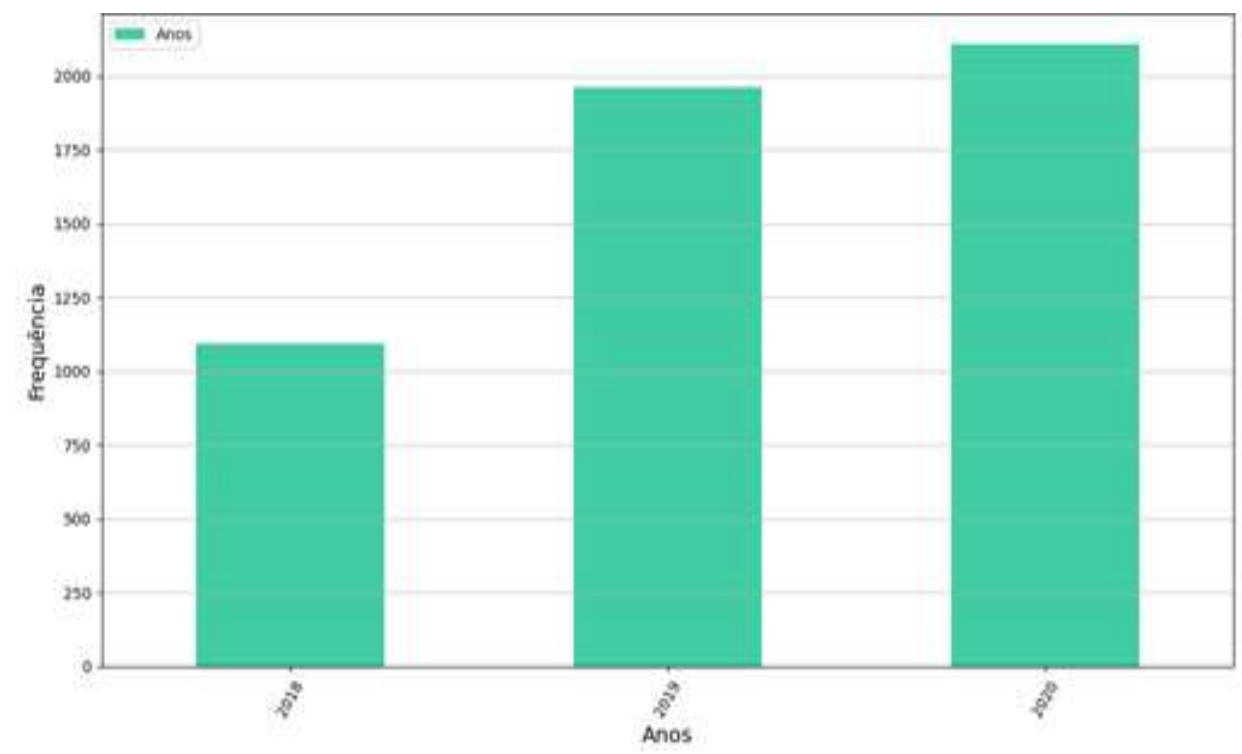

Fonte: Autores (2021).

Esse aumento de ocorrências de crimes cibernéticos observado na pesquisa pode estar relacionado a crescente utilização e acesso à internet em todos os setores sociais, conforme argumenta Marra (2019, p.163) “A Internet ultrapassou os limites impostos pelas fronteiras tornando-se, na atualidade, o principal veículo de divulgação da informação, comunicação, comercialização e, inclusive, de práticas delituosas".

Em seguimento a análise dos dados obtidos neste estudo, a Figura 3 apresenta os tipos de crimes cibernéticos ocorridos no município de Belém/PA ao longo do período compreendido de 2018 a 2020.

Figura 3: Análise por tipo de crime.

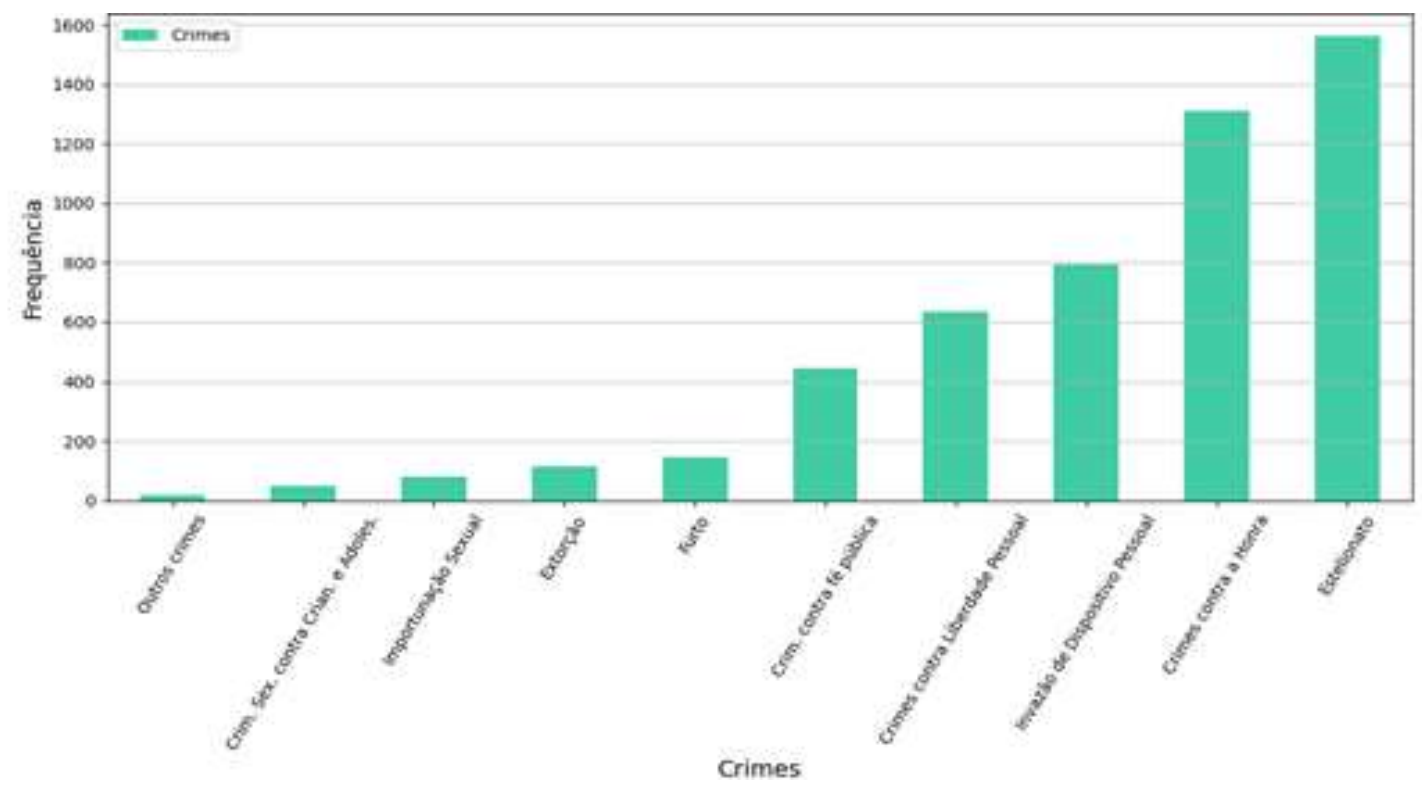

Fonte: Autores (2021). 
Para melhor compreensão das informações extraídas do recorte do banco de dados fornecidos pela SEGUP/PA, faz-se necessário detalhar a tipificação dos crimes inseridos em cada grupo:

- Estelionato por meio de dispositivo eletrônico ou pela internet - Neste estudo, os dados revelaram que o crime de Estelionato teve a maior prevalência ao longo do período de 2018 a 2020, entretanto os dados não esclarecem quais as modalidades foram mais recorrentes.

- Dos Crimes contra a Honra - Observou-se a recorrência dos Crimes de Calúnia, Injúria e Difamação, com maior prevalência, o crime de difamação.

- Invasão de dispositivo informático - Este crime ao qual, teve a terceira maior ocorrência foi inserido ao código penal, em virtude da edição da lei que trata da tipificação dos delitos informáticos, Lei no 12.737/2012.

- Dos crimes contra a liberdade pessoal - Nos dados obtidos, somente foram identificados os crimes de ameaça e de constrangimento ilegal, entretanto a maior prevalência foi do crime de ameaça.

- Dos crimes contra a fé pública - Para esse tipo de crime, somente foram identificados os crimes de falsa identidade, falsidade ideológica e falsificação de documento particular, sendo que, a maior prevalência foi do crime de falsa identidade.

- Furto qualificado - Crime de recorrência relevante, ao qual foi definido pela Lei no 14.155/2021.

- Extorsão - Crime de recorrência relevante entre os dados obtidos. Pode ser praticado através das redes sociais. Os dados não esclarecem quais as modalidades deste crime foram mais recorrentes.

- Importunação sexual - Tipo penal criado pela Lei nº 13.718/2018, a qual altera o Código Penal teve recorrência relevante entre os dados deste estudo.

- Crimes sexuais contra crianças e adolescentes - Embora esse tipo de crime tenha ocupado a penúltima colocação nesta pesquisa, o mesmo, deve ser considerado de grande relevância, dada a sua gravidade e seu caráter perverso. É importante destacar que tais crimes estão previstos na Lei n 11.829/2008.

Em relação à faixa etária das vítimas de crimes cibernéticos, observa-se que a ocorrência prevalente é na fase adulta, pode-se entender que é a mesma fase em que as pessoas têm acesso às tecnologias de forma irrestrita. A baixa ocorrência de registro de crimes cibernéticos tanto na fase de crianças quanto de adolescentes pode ser justificada em função de que nessas faixas etárias costumam ser monitorados no uso dessas tecnologias.

À vista disso, na faixa etária dos idosos, embora o número de ocorrência se apresente relativamente baixo, indica que essa categoria também é alvo dos criminosos cibernéticos, uma vez que, essa geração, mesmo com algumas dificuldades em operacionalizar determinadas tecnologias, vem ganhando cada vez mais acesso às ferramentas tecnológicas, como avaliam Almeida et al (2019) ao concluírem que os idosos também foram abarcados na ascendência das tecnologias porque estas podem lhes proporcionar maior autonomia, bem-estar e integração social. Figura 4. 
Research, Society and Development, v. 11, n. 1, e43411125214, 2022

(CC BY 4.0) | ISSN 2525-3409 | DOI: http://dx.doi.org/10.33448/rsd-v11i1.25214

Figura 4: Análise por faixa etária das vítimas.

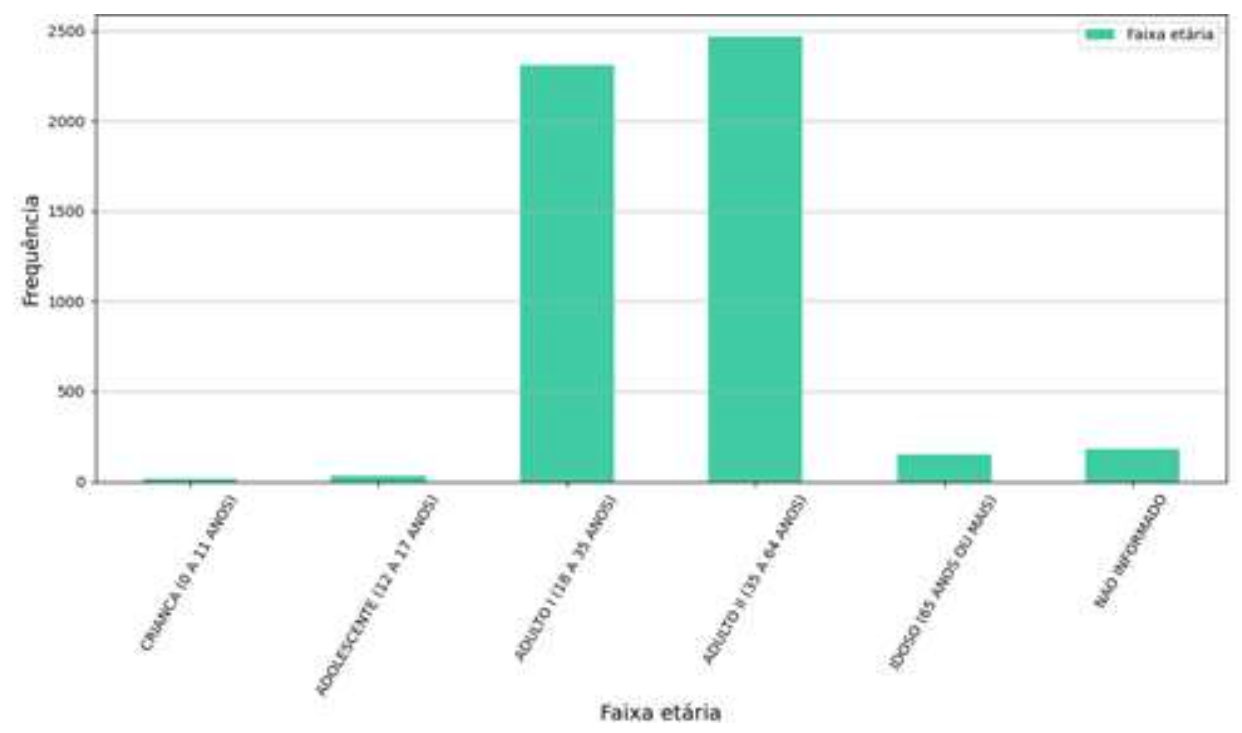

Fonte: Autores (2021).

Ao analisar os dados sobre as profissões das vítimas de crimes cibernéticos, foram identificadas ocorrências nos mais diversos setores profissionais, indicando que qualquer pessoa pode se tornar uma vítima em potencial independente da área profissional em que atua. Conforme pode ser observado na Figura 5.

Figura 5: Análise por profissão das vítimas.

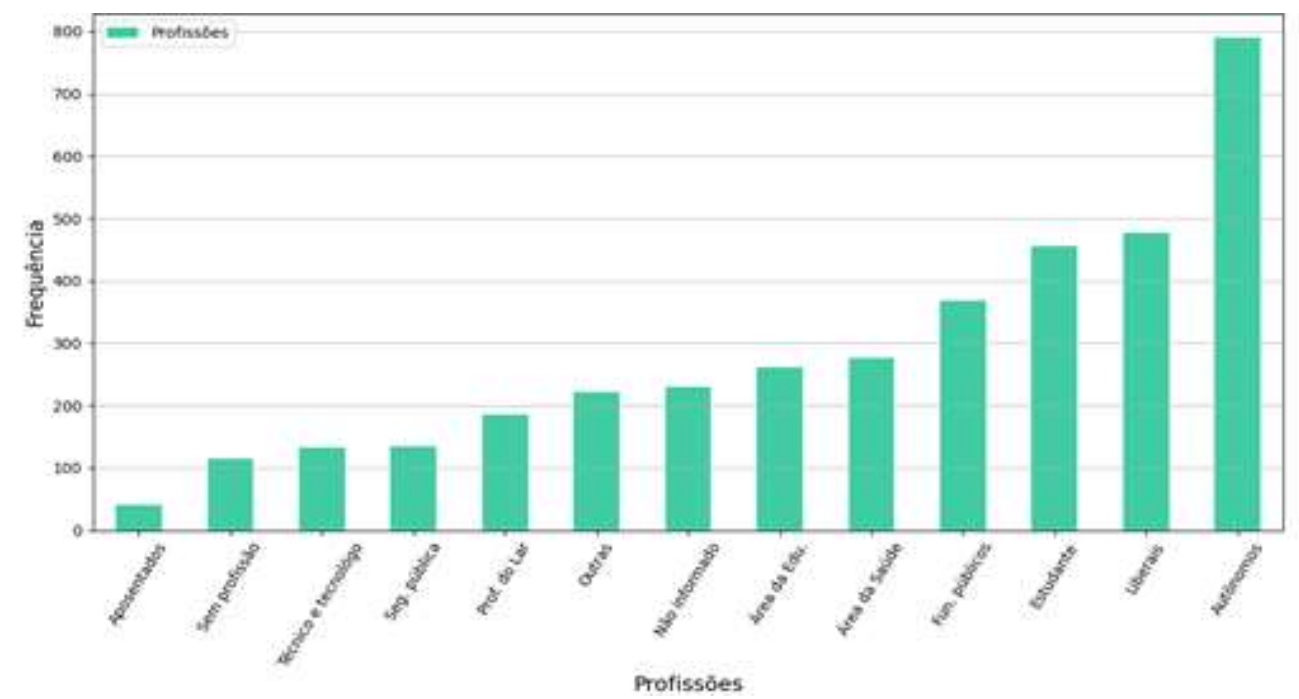

Fonte: Autores (2021).

Em relação a análise das vítimas de crimes cibernéticos por sexo, os dados revelaram que houveram mais registro de ocorrência por pessoas do sexo feminino, entretanto a diferença de ocorrências registradas por pessoas do sexo masculino foi inexpressiva conforme mostra a Figura 6. 
Figura 6: Análise de vítimas por sexo.

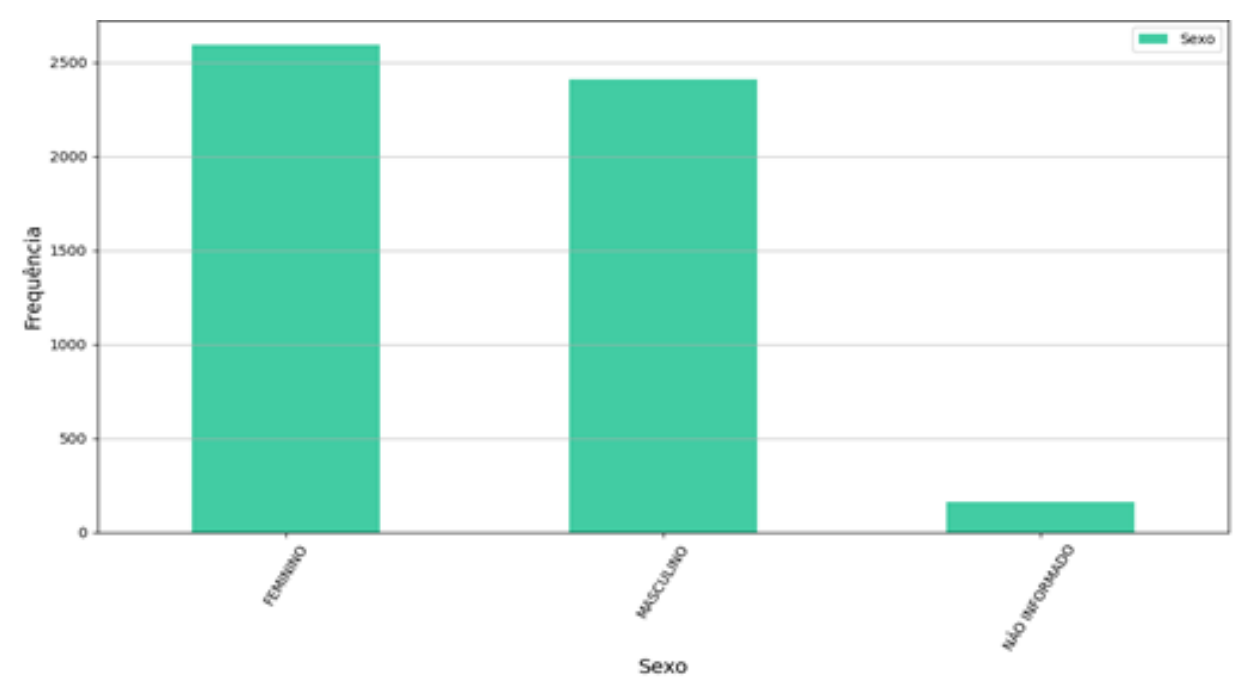

Fonte: Autores (2021).

Ao analisar os registros de ocorrências por regiões, é importante destacar que o município de Belém/PA de acordo com a Lei no 7. 806-30/07/1996, possui 72 bairros e o município está dividido em 08 (oito) Distritos Administrativos (IBGE, 2021). Assim discriminados com seus respectivos bairros:

- Distrito Administrativo de Belém - DABEL - Bairros: Batista Campos, Nazaré, Campina, Cidade Velha, Reduto, São Brás, Umarizal e Marco.

- Distrito Administrativo do Guamá - DAGUA - Bairros: Canudos, Condor, Cremação, Guamá, Jurunas, Montese (Terra Firme).

- Distrito Administrativo da Sacramenta - DASAC - Bairros: Barreiro, Fátima, Marancangalha, Miramar, Pedreira, Sacramenta e Telégrafo.

- Distrito Administrativo do Benguí - DABEN - Bairros: Benguí, Cabanagem, Coqueiro, Parque verde, Pratinha, São Clemente, Tapanã e Uma.

- Distrito Administrativo do Entroncamento - DAENT - Bairros: Águas Lindas, Castanheira, Aurá, Curió-Utinga, Guanabara, Mangueirão, Souza, Val-de-Cans e Universitário.

- Distrito Administrativo de Icoaraci - DAICO - Bairros: Águas negras, Agulha, Campina de Icoaraci, Cruzeiro, Maracacuera, Paracuri, Parque Guajará, Ponta Grossa, Tenoné e Antônio Lemos.

- Distrito Administrativo de Mosqueiro - DAMOS - Bairros: Aeroporto, Ariramba, Baia do Sol, Bonfim, Carananduba, Caruará, Chapéu Virado, Farol, Mangueiras, Maracajá, Marahú, Murubira, Natal do Murubira, Paraíso, Porto Arthur, Praia Grande, São Francisco, Sucurijuquara e Vila.

- Distrito Administrativo de Outeiro - DAOUT - Bairros: Água Boa, Brasília, Itaiteua e São João do Outeiro.

Isto posto, foi possível identificar que a maior ocorrência de vítimas de crimes cibernéticos reside no Distrito Administrativo de Belém - DABEL, sendo este, o Distrito mais centralizado e que engloba os bairros mais nobres da capital do Estado, conforme apresenta a Figura 7. 
Figura 7: Análise de vítimas por Distrito Administrativo do município de Belém/PA.

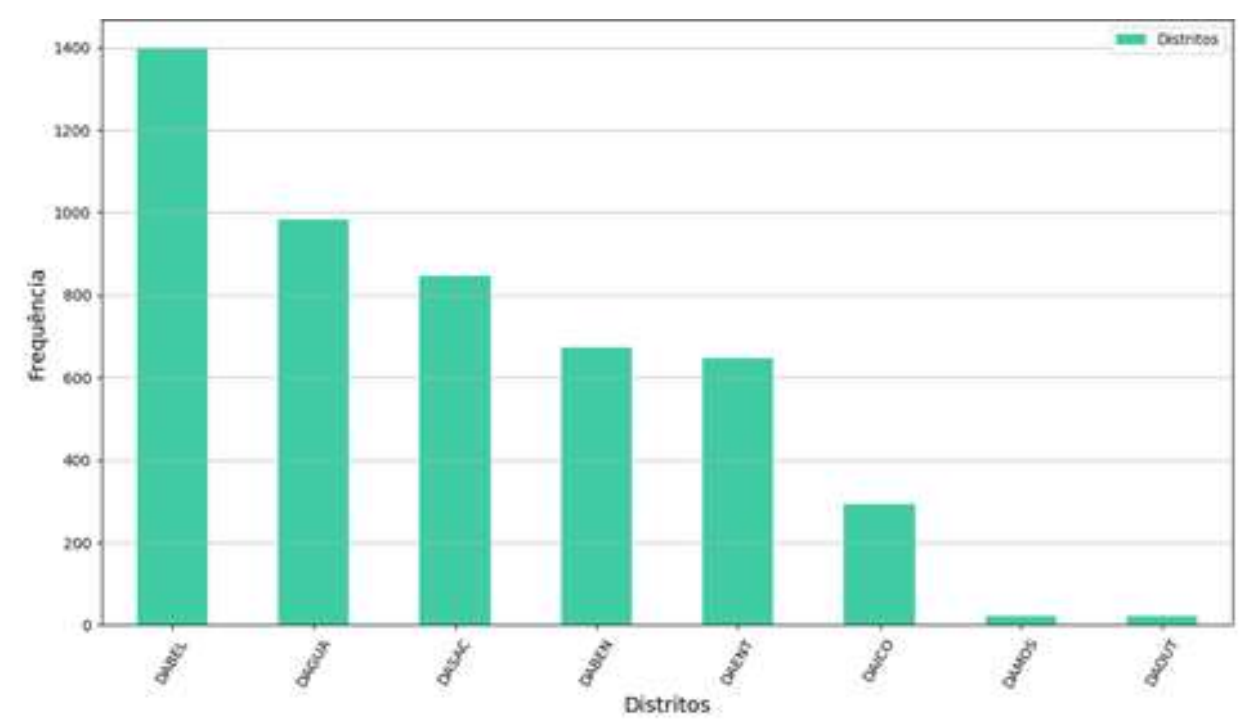

Fonte: Autores (2021).

\section{Conclusão}

Através deste estudo e de acordo com constante no banco de dados da Secretaria de Segurança Pública do Estado do Pará, foi possível fazer um balanço acerca dos principais crimes Cibernéticos ocorridos no município de Belém/PA, bem como foi possível classificá-los e identificar o perfil das vítimas desses crimes no período de 2018 a 2020.

Assim, foi observado que o crime de maior destaque foi o crime de Estelionato, seguido dos crimes contra honra (calúnia, injúria e difamação) e o crime de invasão de dispositivo informático. Notou-se ao perfil das vítimas quanto ao sexo, que há uma prevalência maior no sexo feminino, quanto ao quesito profissão, foi identificado vítimas nos mais variados seguimentos profissionais e em relação a faixa etária, a maior prevalência está entre os adultos de 35 a 65 anos de idade. Quanto à região de Belém com maior ocorrência de crimes cibernéticos foi no distrito central do município, onde se concentram os bairros de classe média alta da capital do Estado do Pará.

Deste modo, a pesquisa possibilitou ampliar os conhecimentos sobre a dinâmica dos crimes cibernéticos, para poder traçar um perfil das vítimas destes ilícitos. Sendo assim, espera-se que o conhecimento produzido seja de grande valia para o desenvolvimento de importantes trabalhos e até mesmo servir de inspiração para implementação de políticas públicas de segurança que trarão benefícios tanto para sociedade acadêmica quanto para a sociedade em geral.

\section{Agradecimentos}

A Secretaria de Segurança Pública do Estado do Pará - SEGUP/PA pelo fornecimento dos dados utilizados na presente pesquisa e ao Programa de Pós-Graduação em Ciências Forense em nível de Mestrado Profissional, da Universidade Federal do sul e Sudeste do Pará - UNIFESSPA, pelo suporte oferecido a esta pesquisa.

\section{Referências}

Almeida, C., Costa, C., Monteiro, M. J., Rainho, C., Barroso, I., Castro, J., Raimundo, F. \& Rodrigues, V. (2019). Utilização de Novas tecnologias por Idosos Institucionalizados. Revista Motricidade. 15(4), 31-35.

Azevedo, J. C., et al. (2015). The Controversies of Self - From(info) Ethics to Cyber Terror. Journal of Information Systems and Technology Management. $12(3), 577-594$

Benson, V., McAlaney, J., \& Frumkin, L. A. (2018). Emerging Threats for the Human Element and Countermeasures in Current Cyber Security Landscape. In Psychological and Behavioral Examinations in Cyber Security. 266-271. IGI Global. 
Brasil. (2012). Lei n ${ }^{\circ}$ 12.735, de 30 de novembro de 2012. Altera o Decreto-Lei no 2.848, de 7 de dezembro de 1940 - Código Penal, o Decreto-Lei no 1.001 , de 21 de outubro de 1969 - Código Penal Militar, e a Lei $\mathrm{n}^{\circ}$ 7.716, de 5 de janeiro de 1989, para tipificar condutas realizadas mediante uso de sistema eletrônico, digital ou similares, que sejam praticadas contra sistemas informatizados e similares; e dá outras providências. http//www.planalto.gov.br/ccivil_03_ato2011-2014/2012/lei/l12735.htm.

Brasil. (2012). Lei $\mathrm{n}^{\circ}$ 12.737, de 30 de novembro de 2012. Dispõe sobre a tipificação criminal de delitos informáticos; altera o Decreto-Lei ${ }^{\circ} 2.848$, de 7 de dezembro de 1940 - Código Penal; e dá outras providências. http//www.planalto.gov.br/ccivil_03_ato2011-2014/2012/lei/112737.htm.

Brasil. (1940). Decreto-Lei $\mathrm{n}^{\mathrm{o}} 2.848$, de 07 de dezembro de 1940 . Código Penal Brasileiro. www2.senado.leg.br/bdsf/bitstream/handle/id/529748/código_penal_1ed.pdf.

Brasil. (2014). Lei $\mathrm{n}^{\mathrm{o}} 12.965$, de 23 de abril de 2014. Estabelece princípios, garantias, direitos e deveres para o uso da internet no Brasil. http//www.planalto.gov.br/ccivil_03_ato2011-2014/2012/lei/112965.htm.

Brasil. (1988). Constituição da República Federativa do Brasil de 1988. Disponível em: planalto.gov.br/ccivil_03/constituicao/ constituicao.htm.

Brasil (2021). Instituto Brasileiro de Geografia e Estatística - IBGE. Cidades e Estados. https://www.ibge.gov.br/cidades-e-estados/pa/belem.html.

Cassanti, M. O. (2014). Crimes Virtuais Vítimas Reais. Editora Brasport livros e multimídia LTDA.

Correia, P. M. A. R., Jesus, I. O. A. (2016). Combate às transferências bancárias ilegítimas pela Internet no direito português: entre as experiências domésticas e políticas globais concertadas. Revista Direito GV. 12(2). 542-563.

Crespo, M. X. F. (2011). Crimes Digitais. Editora Saraiva.

Demeau, E., Monroy, M. E. V. \& Jeffrey, K. (2019). Wildlife trafficking on the internet: a virtual market similar to drug trafficking? Revista Criminalidad, 61(2): $101-112$

Garcia, P. S., Macadar, M. \& Luciano, E. M. (2018). A influência da injustiça organizacional na motivação para a prática de crimes cibernéticos. Journal of Information Systems and Technology Management - Jistem USP. 15, e 201815002.

Gerhardt, T. E. \& Silveira, D. T. (2009). Métodos de pesquisa. Editora da UFRGS.

Marra, F. B. (2019). Desafios do direito na era da internet: Uma breve análise sobre crimes cibernéticos. Revista campo jurídico, Barreiras-BA, 7(2),.145-167.

Mendes, G. F., Coelho, I. M. \& Branco, P. G. G. (2008). Curso de Direito Constitucional. Editora Saraiva. (4a ed.).

Menezes, M. R. C. de \& Cavalcanti, V. R. S. (2017). Mulher Jovem e Cibercultura: Liberdade, Subordinação e Reminiscências Patriarcais no meio Virtual. Revista Ex aequo (35), 33-47.

Pará. (1996). Lei no 7. 806, de 30 de julho de 1996. Delimita as áreas que compõem os bairros de Belém, revoga a lei no $7.245 / 84$, e dá outras providências. https://cm-belem.jusbrasil.com.br/legislacao/581764/lei-7806-96.

Viana FRM, Meneghetti FK. Is It Crowdsourcing or Crowdsensing? an Analysis of Human Participation in DigitaL Platforms in the Age of Surveillance Capitalism. REAd. 26(1), 176-209. 2020

Wendt, E. \& Jorge, H. V. N. (2013). Crimes Cibernéticos Ameaças e Procedimentos de Investigação. Editora Brasport livros e multimídia LTDA. (2a ed.)

Zuboff, S. (2020). A era do capitalismo de vigilância: a luta por um ser humano futuro na nova fronteira do poder. Tradução de George Schlesinger. Intrínseca. 